Case Report

\title{
Hypocalciuric Hypercalcemia due to Impaired Renal Tubular Calcium Excretion in a Type 2 Diabetic Patient
}

\author{
Sihao Yang, ${ }^{1,2}$ Yan Ren, ${ }^{1}$ Xi Li, ${ }^{1}$ Haoming Tian, ${ }^{1}$ Zhenmei An, ${ }^{1}$ and Tao Chen ${ }^{1}$ \\ ${ }^{1}$ Department of Endocrinology and Metabolism, West China Hospital of Sichuan University, Chengdu, China \\ ${ }^{2}$ Department of Chinese Traditional Medicine, The Second People's Hospital of Yibin, Yibin, China \\ Correspondence should be addressed to Zhenmei An; 848948343@qq.com and Tao Chen; dr.chentao@qq.com
}

Received 17 November 2016; Accepted 9 January 2017; Published 11 April 2017

Academic Editor: Wayne V. Moore

Copyright (C) 2017 Sihao Yang et al. This is an open access article distributed under the Creative Commons Attribution License, which permits unrestricted use, distribution, and reproduction in any medium, provided the original work is properly cited.

\begin{abstract}
The case we presented here was a 73-year-old gentleman, who was admitted to endocrinology department due to recurrent fatigue for 1 year. He had medical histories of type 2 diabetes for 18 years and developed CKD 4 years ago. He also suffered from dilated cardiomyopathy, and coronary heart disease, moderate sleep apnea syndrome, primary hypothyroidism, and gout. His treatment regimen was complicated which included Caltrate D and compound $\alpha$-keto acid (1200 mg calcium/d). Laboratory examination revealed that his serum calcium level elevated, 24-hour urine calcium output decreased, PTH level was suppressed, and 25-hydroxyvitamin D was in normal low range. No other specific abnormalities were found in serum bone turnover markers, ultrasonography, computed tomography, and bone scintigraphy. The diagnosis was suggested to be hypocalciuric hypercalcemia but was different from familial or acquired hypocalciuric hypercalcemia which were featured by elevated PTH level. The patient was asked to restrict calcium intake and to take diuretics; then his serum calcium level gradually lowered. In brief, patients with CKD could present with hypocalciuric hypercalcemia due to impaired renal calcium excretion. In this case, calcium restriction should be applied for treatment.
\end{abstract}

\section{Introduction}

Hypercalcemia related to PTH, malignancy diseases (PTHrP or destruction), and vitamin D metabolites usually could be easily diagnosed according to clinical setting [1]. However, in other cases, especially in cases with PTH independent hypercalcemia, the etiology is often difficult to identify. A published review summarized the rare causes of hypercalcemia and showed the potential mechanisms including calcitriol overdosage, occult milk-alkali syndrome, some medications (e.g., omeprazole, theophylline toxicity, and growth hormone), and other diversity causes [2]. Other recent studies showed that sarcoidosis [3], granulomatosis/granuloma $[4,5]$, diabetic ketoacidosis [6], and methylmethacrylate for cosmetic purposes [7] could also be causes for PTH independent hypercalcemia. However, hypercalcemia due to impaired renal calcium excretion was rarely reported. Here, we presented a case of hypocalciuria hypercalcemia with suppressed PTH levels. The mechanism could be impaired renal tubular calcium regulation.

\section{Case Report}

The patient was a 73-year-old man who was admitted in September 21, 2015, due to recurrent fatigue for 1 year. He was diagnosed as type 2 diabetes 18 years ago, developed chronic kidney disease 4 years ago, and began to take compound $\alpha$ keto acid (2520 mg three times a day, approximately containing $600 \mathrm{mg}$ calcium element). Six years ago, he was diagnosed with osteoporosis and began to take Caltrate D $(600 \mathrm{mg}$ calcium element) and Alphacalcidol $(0.5 \mu \mathrm{g})$ daily. One year ago, the patient began to feel fatigue. Laboratory tests showed serum calcium elevated to $3.41 \mathrm{mmol} / \mathrm{L}$. After stopping Caltrate D and Alphacalcidol, it fluctuated between 2.24 and $2.93 \mathrm{mmol} / \mathrm{L}$. Two months ago, he felt fatigue again and was referred to endocrinology department. Laboratory tests showed elevated serum calcium level $(3.03 \mathrm{mmol})$. No other clinical significant changes were found in thyroid function, blood gas analysis, immunologic test, protein electrophoresis, tumor markers, ACTH, and plasma total cortisol levels. 


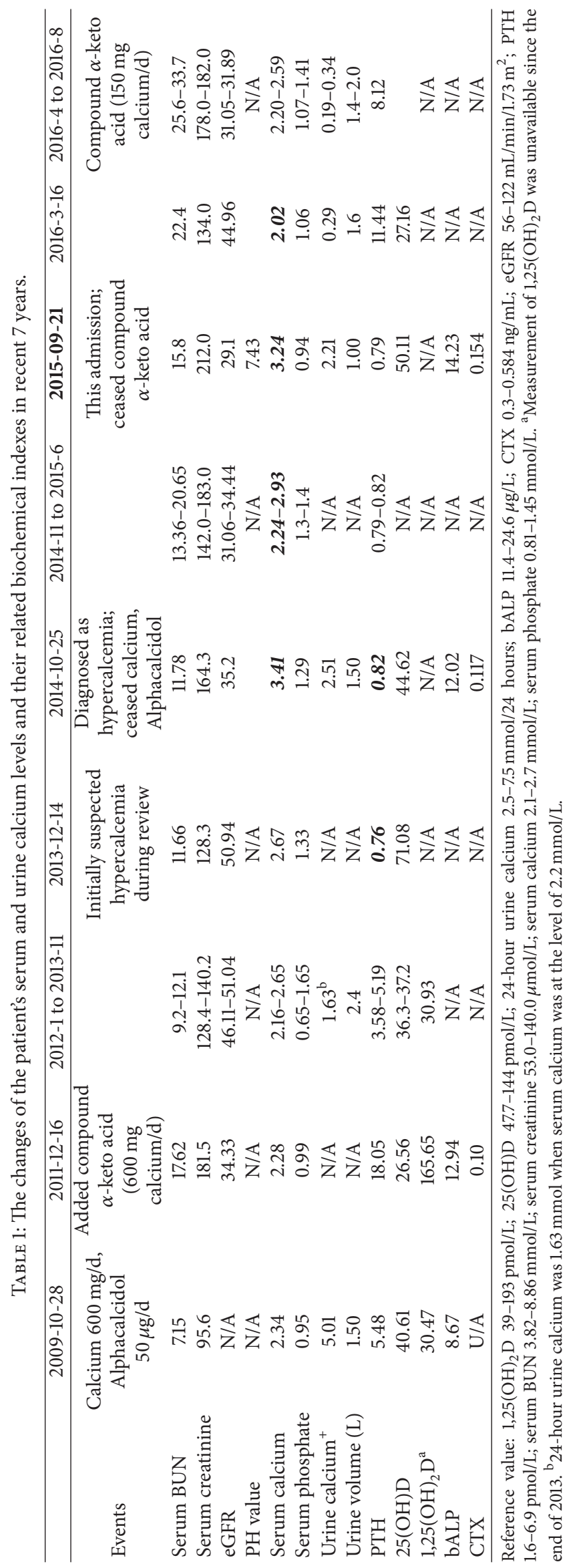


We then comprehensively reviewed his laboratory reports in recent years (Table 1). We found his serum calcium began to raise at the end of 2013, as indicated by suppressed PTH (serum calcium $2.67 \mathrm{mmol} / \mathrm{L}, \mathrm{PTH} 0.76 \mathrm{pmol} / \mathrm{L}$ ), and then raised up to $3.41 \mathrm{mmol} / \mathrm{L}$ in 2014 . After calcium and vitamin $\mathrm{D}$ restriction, his serum calcium fluctuated between 2.24 and $2.93 \mathrm{mmol} / \mathrm{L}$, and $\mathrm{PTH}$ were consistently suppressed (from 0.79 to $0.82 \mathrm{pmol} / \mathrm{L}$ ). Further evaluation showed that his urine calcium output decreased (1.63-2.51, reference value $2.5-7.5 \mathrm{mmol} / 24$ hours) when serum calcium increased. Meanwhile, his serum 25-hydroxyvitamin D, bALP, and CTX were all in low levels. No specific signs were found by DEXA, chest and abdominal computed tomography, and bone scintigraphy.

Taken together, we suggested that this patient developed a clinical condition, featured by hypocalciuric hypercalcemia and suppressed PTH level. He was asked to cease compound $\alpha$-keto acid, restrict milk intake, increase water intake, and use diuretics. His serum calcium gradually returned to normal. On March 16, 2016, he experienced recurrent cramp in both legs. Laboratory workup showed his serum calcium decreased to $2.02 \mathrm{mmol} / \mathrm{L}$, and PTH elevated to $11.44 \mathrm{nmol} / \mathrm{L}$. His treatment was adjusted to compound $\alpha$-keto acid two tablets one day, three times one week, and he was asked to monitor serum calcium every month.

\section{Discussion}

Hypocalciuric hypercalcemia as familial pattern was wellknown [1]. In recent two decades, acquired hypocalciuric hypercalcemia was reported and was supposed to be resulting from autoantibody against calcium-sensing receptor (CSRP) $[8,9]$. A typical feature of acquired hypocalciuric hypercalcemia slightly elevated PTH level, which is due to increased set point of parathyroid cell for serum calcium. While, in this case, PTH was suppressed when serum calcium increased, and PTH elevated when serum calcium decreased, indicating normal function of CSRP in this patient's parathyroid gland. Thus, we deduced that his hypercalcemia was caused by impaired calcium excretion from urine.

In normal person, about $59 \%$ of total serum calcium is filtered into crude urine. Then, $90 \%$ of those were reabsorbed by proximal tubules, henry loop, and early distal tubules and nearly $10 \%$ reabsorbed by early collecting ducts and late distal tubular. The latter portion is relatively few but more important in calcium hemostasis because it is highly dependent on the blood calcium ion concentration. A slightly elevation of serum calcium level, under the regulation of $\mathrm{PTH}$, will result in strikingly increasing calcium excretion from urine $[8,10]$.

In this case, the patient's serum PTH level changed corresponding to alteration of serum calcium level but failed to maintain serum calcium to the normal range. Thus, we proposed that the patient's hypocalciuric hypocalcemia resulted from impaired response of late distal tubular and early collecting ducts to the changed PTH level. We searched Medline (PubMed, update to May 2, 2016) using Mesh term "Hypocalciuric Hypercalcemia" but failed to retrieve any similar reports. We were unable to perform renal biopsy because of the patient's refusal. So, we could not, regrettably, demonstrate the exact mechanism of how the patient's renal tubular failed to respond to changed serum calcium level. The differential diagnosis of hypercalcemia without clear etiology is often very difficult; therefore, the case we presented here might provide some valuable information for future clinical practice.

\section{Conclusion}

PTH independent hypocalcaemia could be caused by decreased urine calcium excretion in patients with complicated clinical conditions. Calcium restriction and carefully monitoring were the key points in treatment.

\section{Competing Interests}

The authors declare that they have no competing interests.

\section{Authors' Contributions}

Sihao Yang and Yan Ren contributed equally to this paper.

\section{References}

[1] F. Bringhurst, M. Demay, and H. Kronenberg, "Hormones and disorders of mineral metabolism," in Williams Textbook of Endocrinology, S. Melmed, K. Polonsky, P. Larsen, and H. Kronenberg, Eds., pp. 1260-1277, Elsevier Sauders, Philadelphia, Pa, USA, 12th edition, 2011.

[2] T. P. Jacobs and J. P. Bilezikian, "Clinical review: rare causes of hypercalcemia," Journal of Clinical Endocrinology and Metabolism, vol. 90, no. 11, pp. 6316-6322, 2005.

[3] R. Lupica, M. Buemi, A. Campenni et al., "Unexpected hypercalcemia in a diabetic patient with kidney disease," World Journal of Nephrology, vol. 4, no. 3, pp. 438-443, 2015.

[4] P. Hardy, P. H. Morinière, B. Tribout et al., "Liver granulomatosis is not an exceptional cause of hypercalcemia with hypoparathyroidism in dialysis patients," Journal of Nephrology, vol. 12, no. 6, pp. 398-403, 1999.

[5] S. M. Hindi, Y. Wang, K. D. Jones et al., "A case of hypercalcemia and overexpression of CYP27B1 in skeletal muscle lesions in a patient with HIV infection after cosmetic injections with polymethylmethacrylate (PMMA) for wasting," Calcified Tissue International, vol. 97, no. 6, pp. 634-639, 2015.

[6] T. Makaya, S. Chatterjee, P. Arundel, C. Bevan, and N. P. Wright, "Severe hypercalcemia in diabetic ketoacidosis: a case report," Diabetes Care, vol. 36, no. 4, article no. e44, 2013.

[7] D. V. Rados and T. W. Furlanetto, "An unexpected cause of severe and refractory PTH-independent hypercalcemia: case report and literature review," Archives of endocrinology and metabolism, vol. 59, no. 3, pp. 277-280, 2015.

[8] J. C. Pallais, O. Kifor, Y.-B. Chen, D. Slovik, and E. M. Brown, "Acquired hypocalciuric hypercalcemia due to autoantibodies against the calcium-sensing receptor," New England Journal of Medicine, vol. 351, no. 4, pp. 362-369, 2004.

[9] N. Makita, J. Sato, K. Manaka et al., "An acquired hypocalciuric hypercalcemia autoantibody induces allosteric transition among active human Ca-sensing receptor conformations," Proceedings of the National Academy of Sciences of the United States of America, vol. 104, no. 13, pp. 5443-5448, 2007. 
[10] A. Guyton and J. Hall, "Renal regulation of potassium, calcium, phosphate, and magnesium; Integration of renal mechanisms for control of blood volume and extracellular fluid volume," in Guyton and Hall Textbook of Medical Physiology, pp. 371-373, Elsevier Saunders, Philadelphia, Pa, USA, 12th edition, 2006. 


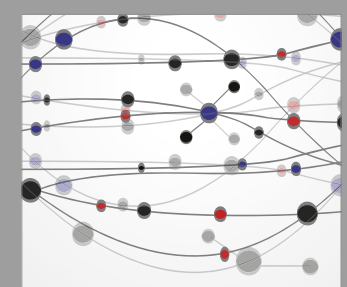

The Scientific World Journal
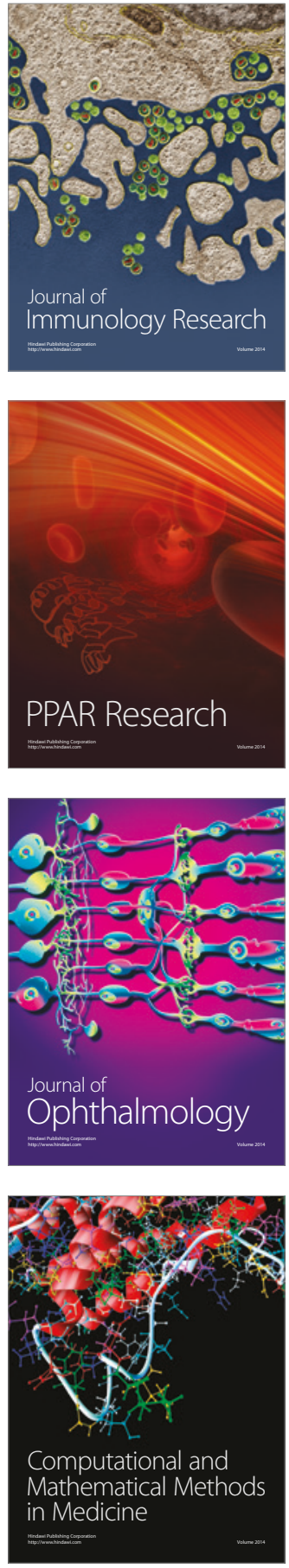

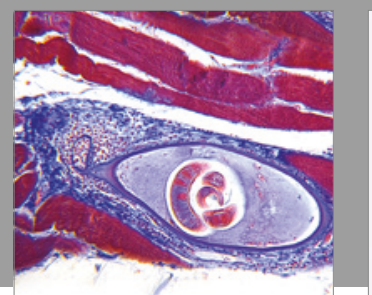

Gastroenterology Research and Practice
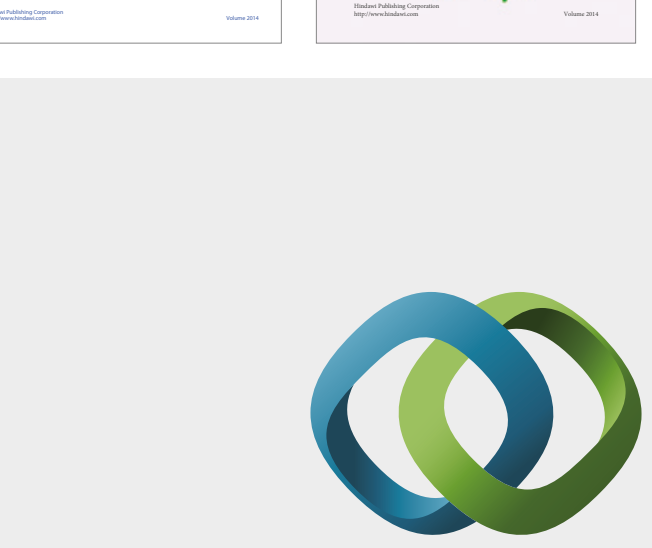

\section{Hindawi}

Submit your manuscripts at

https://www.hindawi.com
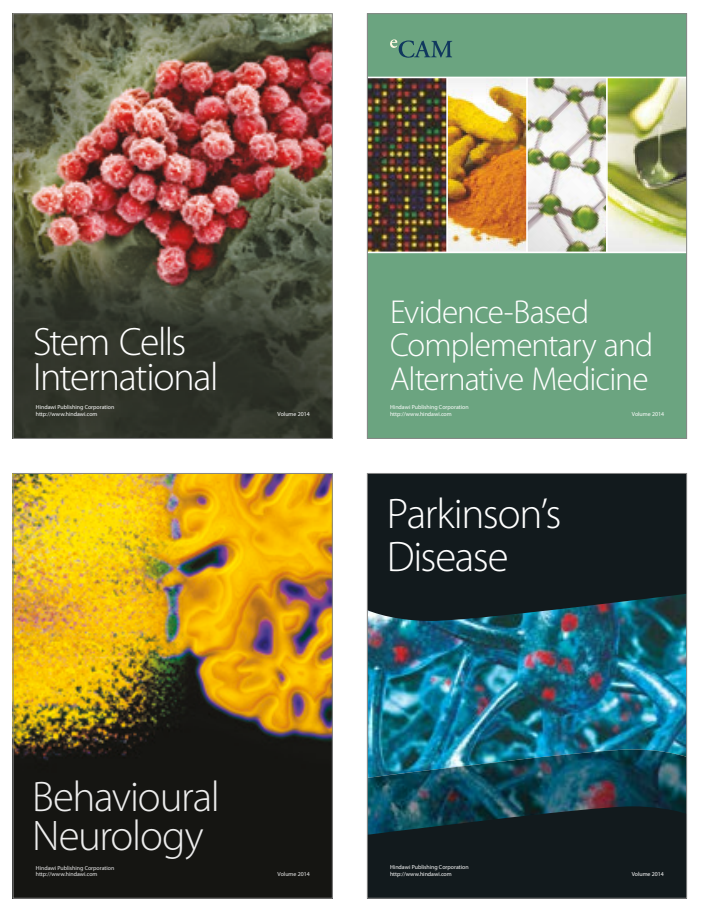
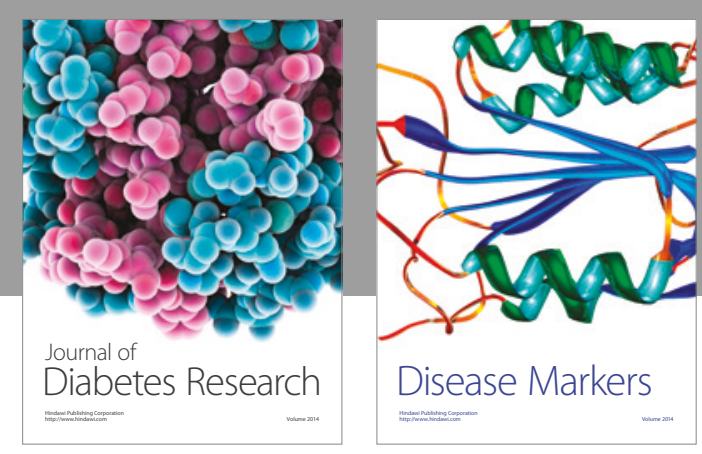

Disease Markers
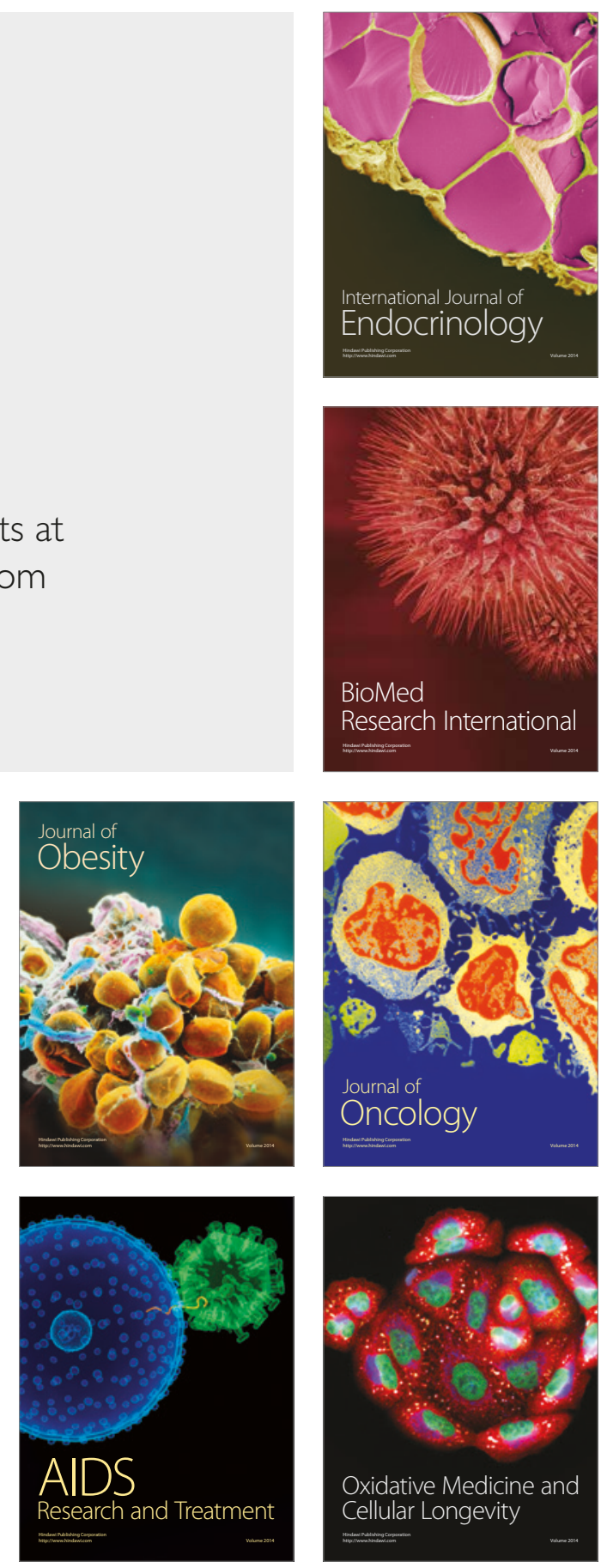